\title{
Buenas prácticas para la mejor conducción del procedimiento en el arbitraje comercial internacional
}

\author{
Juan Eduardo Figueroa Valdés*** \\ Recibido/Received: 07/01/2016 \\ Aceptado/Accepted: 19/08/2016
}

SUMARIO: 1. Introducción. 2. Correcto desempeño como árbitro. 3. Correcto desempeño como abogado. 4. Correcto desempeño como partes. 5. Correcto desempeño como secretario arbitral. 6. Consideraciones finales.

PALABRAS CLAVES: buenas prácticas, procedimiento, árbitro, abogado, representación de parte, partes, secretario arbitral

KEYWORDS: good practices, proceedings, arbitrator, attorney, party representation, parties, arbitral secretary

RESUMEN: Los arbitrajes internacionales suelen congregar actores de los más variados orígenes y culturas, razón por la cual son necesarias normas internacionalmente aceptadas y uniformes para regir el procedimiento arbitral. Las institu-

* Árbitro I.C.D.R, Árbitro del Centro de Arbitrajes de la Cámara de Comercio de Santiago de Chile, Arbitro Centro de Arbitrajes de U. Católica de Lima, Perú, Árbitro de Cámara de Comercio Brasil-Canadá, Árbitro FIESP, Brasil, Arbitro Instituto de Ingenieros Sao Paulo, Brasil. Miembro del grupo de arbitraje internacional para América Latina de la CCI, Profesor de la Universidad de los Andes. Abogado Integrante de la Corte Suprema de Chile., LL.M en Derecho Internacional, Comercio, Inversiones y Arbitraje por la Universidad de Heidelberg, Alemania.

** Este artículo ha sido preparado con la colaboración de la abogada Luciana Rosa Rodrígues, LLM en Derecho Internacional, Comercio, Inversiones y Arbitraje por la U. de Heidelberg, Alemania y Master en Ciencias Sociales por la Universidad Federal de Santa María-RS- Brasil.

J. FigUEROA, "Buenas prácticas para la mejor conducción del procedimiento en el arbitraje comercial internacional”, Revista Ecuatoriana de Arbitraje, No. 7, 2015. 
ciones arbitrales internacionales ofrecen reglamentos que sirven para uniformar las normas a seguir, pudiendo las partes elegir cuál de ellos adoptar, además de la sede del arbitraje y el idioma del procedimiento arbitral. Existen diversas directrices y reglas que orientan tanto el trabajo de los árbitros como el de los abogados, partes y secretarios arbitrales. El presente artículo analiza las buenas prácticas que todos los actores involucrados debieran observar para que el árbitro cumpla con su función de entregar una solución justa, expedita y especializada dentro de plazos razonables.

\begin{abstract}
International arbitrators generally congregate actors from different origin and cultures. For this reason, internationally acceptable regulations are necessary to rule the proceedings. Internationals arbitration center serve to standardize rules and the parties may choose which one to follow, choosing also the seat of arbitration and language of the proceedings. There are many guidelines, rules and regulations that guide the work not only of the arbitrator buy also for lawyers, parties and arbitral secretaries. This article discusses best practices that all actors should observe in order that arbitrator fulfill its function of delivering a fair, expeditious, and specialized solution within a reasonable period of time.
\end{abstract}

\title{
1. INTRODUCCIÓN
}

Las buenas prácticas en el arbitraje comercial internacional buscan fortalecer la confiabilidad en el sistema arbitral y asegurar la eficiencia, economía y transparencia del procedimiento arbitral. Dado que el árbitro carece del poder de coacción del Estado, es muy importante que todos los involucrados tengan una conducta colaborativa para que el arbitraje no pierda su razón de existir, o sea, una solución expedita, segura, especializada, confidencial y económica. 
Para un exitoso desempeño del arbitraje comercial internacional en América Latina, resulta de especial interés recoger las buenas prácticas internacionales, uniformemente aceptadas, que se encuentran reflejadas en diversas reglas del soft law, aplicables tanto para árbitros, como para los abogados, las partes y el secretario del tribunal arbitral, que han ido desarrollándose especialmente en las últimas décadas.

En razón de ello trataremos, en particular, a partir de dichas directrices, cuál debiera ser la forma de actuar tanto del árbitro, del abogado, de las partes como del secretario del tribunal arbitral, de modo que se logren los objetivos antes planteados, teniendo un procedimiento arbitral con reglas conocidas, uniformemente aceptadas, sin sorpresas y que permita que cada parte pueda hacer valer oportunamente sus derechos, y rendir sus pruebas $y$, en definitiva, que se dicte un laudo que pueda ser ejecutado, y no se vea expuesto a ser anulado o a no ser reconocido al requerirse su ejecución.

\section{CoRRECTO DESEMPEÑo COMO ÁRBITRO}

Debido a la importancia del tema, algunos estándares éticos para los árbitros han sido ya codificados hace varias décadas. Así, por ejemplo, en el año 1987 la IBA publicó sus recomendaciones éticas para árbitros internacionales, que establecen que los árbitros internacionales deben ser imparciales, independientes, competentes, diligentes y discretos. Recientemente en el año 2014 la IBA publicó también las "Directrices sobre los Conflictos de Intereses en el Arbitraje Internacional." Poseen también recomendaciones a los árbitros, entre otros, el Chartered Institute of Arbitrators $(\mathrm{CIArb})^{1}$, el Club Español de Arbitraje ${ }^{2}$.

Es usual escuchar que el arbitraje vale lo que vale el árbitro. Pero cabe preguntarse ¿qué es lo que hace que un árbitro sea

1. Para más información, véase $<w w w . c i a r b . o r g ~>$.

2. Para más información, véase $<w w w . c l u b a r b i t r a j e . c o m>$. 
bueno? Es habitual que cuando se habla del tema, se piensa en independencia e imparcialidad, por el hecho de que éstas son la clave de la institución arbitral, cuyo desarrollo depende de la confianza de los operadores. Según Jesús Remón ${ }^{3}$, la independencia es un concepto objetivo, vinculado a las relaciones pasadas o presentes del árbitro con las partes y susceptible, por tanto, de verificación, a diferencia de la imparcialidad que es una actitud subjetiva del árbitro respecto a la disputa y las posiciones de las partes enfrentadas, que se equipara a su neutralidad en el ejercicio de la función arbitral que tiene encomendada. Se refiere a prejuicios que tenga el árbitro por su visión personal de las cosas.

Sin embargo, el umbral de exigencia es mucho mayor, ya que además de ser independientes e imparciales los árbitros deben parecerlos. Ello exige, entre otras cosas, que no guarden estrechas relaciones personales, profesionales o comerciales ni con las partes, con los abogados representantes de éstos, ni con los restantes árbitros; que no tengan un interés directo personal o profesional en el resultado del procedimiento; y que con anterioridad a su designación, no hayan manifestado su opinión sobre el caso concreto a ninguna de las partes.

Las leyes de arbitraje nacionales, siguiendo la Ley Modelo UNCITRAL, consagran el principio de la imparcialidad e independencia de los árbitros como clave de todo el sistema arbitral. Para asegurar la observancia de estos principios, se contemplan, entre otras, las normas siguientes 4

a) Neutralidad: La prohibición a los árbitros de que mantengan relaciones personales, profesionales o comerciales con las partes durante el arbitraje;

b) Transparencia: Antes de la aceptación del cargo, los árbitros deben revelar todas las circunstancias que puedan dar lugar a dudas justificadas acerca de su imparcialidad e independencia (disclosure); $\mathrm{y}$,

3. J. RAMÓN, "Las buenas prácticas en el arbitraje internacional", en C. Soto (Coor.) y D. Revoredo Marsano De Mur (Coor.), Arbitraje Internacional: pasado, presente y futuro, Tomo I, Instituto Peruano de Arbitraje, 2013, p. 597.

4. Ibídem. 
c) Recusación, esto es, el derecho de las partes de recusar o inhabilitar a los árbitros si concurren circunstancias que den lugar a justificadas dudas sobre su imparcialidad o independencia, o si no posee las calificaciones convenidas por las partes.

Por lo tanto, las instituciones que administran arbitrajes deberán velar siempre por la imparcialidad e independencia de los árbitros al confirmar las designaciones o al efectuar sus nombramientos, teniendo en cuenta que el principal elemento que las empresas consideran cuando eligen un árbitro es su reputación ${ }^{5}$. Así, el árbitro debe rechazar su designación si tiene cualquier duda sobre imparcialidad o independencia, como también revelar a las partes si durante el desarrollo del arbitraje se produce cualquier hecho nuevo que ponga en riesgo su independencia o imparcialidad, renunciando al arbitraje si así la situación lo amerita.

En las Directrices de la IBA para Conflictos de Interés en el Arbitraje Internacional (2014), se encuentra una relación de hechos y circunstancias específicas que deben ser reveladas por el árbitro o que justifican su recusación. El listado rojo establece situaciones que implican la falta de imparcialidad y/o independencia del árbitro. El naranja contiene situaciones específicas que -dependiendo de los hechos o las circunstancias particulares del caso-, a los ojos de las partes, puede crear dudas acerca de la imparcialidad o independencia del árbitro y, finalmente, el verde trata de situaciones que, desde un punto de vista objetivo, no son susceptibles de crear un conflicto de intereses. Estos listados, sin embargo, simplifican una realidad muy compleja, de modo que hay que considerar la situación concreta, prevaleciendo siempre las circunstancias particulares de cada caso. Ellas sirven como una mera referencia para los árbitros y las partes.

Con todo, el umbral de exigencia para un buen árbitro, es aún mucho mayor. De acuerdo con DerAINS ${ }^{6}$, además de la indepen-

5. QueEn MARY, University Of LONDON. Internacional Arbitration Survey: Choices in international arbitration. White \& Case LLP, 2010, p. 25. 
dencia e imparcialidad, un buen árbitro también debe tener habilidad de decidir, disponibilidad, capacidad de trabajar duro, diplomacia y neutralidad cultural.

Las partes esperan decisiones del árbitro debidamente fundadas, basadas en su experiencia y estudio acucioso del caso. Un buen árbitro debe saber posicionarse y decidir los asuntos que se presentan en el curso del procedimiento como, por ejemplo, acerca de la admisibilidad de las pruebas ofrecidas, de la solicitud de exhibición de documentos, la forma de rendir las pruebas, etc. Ello implica que el árbitro deba estar familiarizado con el caso desde su inicio, para poder adoptar a tiempo las medidas que sean pertinentes y conducentes a una conducción eficiente del procedimiento arbitral. Al respecto, resultan, por ejemplo, muy útiles las directrices entregadas por la ICC para administrar en forma adecuada un arbitraje ${ }^{7}$.

La disponibilidad para trabajar en el caso también es un tema muy importante. Los arbitrajes generalmente involucran una cantidad considerable de archivadores de documentos complejos, y el buen árbitro debe trabajar y familiarizarse adecuadamente con ellos, lo que implica una gran dedicación de tiempo. El conocido overbooking es una de las razones por las cuales más se atrasan los arbitrajes. Es usual que los árbitros tengan una importante carga de trabajo, pues tienen varios procedimientos arbitrales tramitándose en conjunto, además de la realización de sus demás actividades. Así es recurrente que algunos árbitros tengan dificultades al momento de fijar el calendario de las audiencias. En razón de ello, es conveniente que las partes consulten al árbitro acerca de su disponibilidad antes que sea nominado.

Sobre la conducción eficiente del arbitraje resulta interesante la norma establecida en el Reglamento de la ICC, Artículo 22Y, que dispone: "El tribunal arbitral y las partes deberán hacer todos

6. Y. Derains, "Is Arbitration Only as Good as the Arbitrator? Status, Powers and Role of the Arbitrator", Dossiers of the ICC Institute of World Business Law, Kluwer Law International; International Council for Commercial Arbitration/Kluwer Law International Vol. 8, 2011.

7. Y. DeRAins, N. 6. 
los esfuerzos para conducir el arbitraje de una manera expedita y eficaz en término de costos, teniendo en cuenta la complejidad y el valor de la controversia."

Con el objeto de lograr dicho objetivo, muchas instituciones arbitrales recomiendan la celebración de una conferencia preliminar sobre la conducción del procedimiento ${ }^{8}$, donde las directivas sobre el procedimiento a seguir en el arbitraje sean convenidas.

El buen árbitro debe dirigir el caso, evitando costos innecesarios y pérdida de tiempo. Durante la etapa del inicio del arbitraje deben tratarse aspectos triviales, tales como que los escritos se presenten en forma separada de los documentos, que éstos comiencen con un índice, si se enviarán adicionalmente los documentos en formato electrónico para facilitar su consulta posterior, etc. Por lo tanto, el trabajo del árbitro supone no solamente tener el tiempo y la voluntad de estudiar a fondo la controversia, sino también administrar todo el procedimiento de modo eficaz, siempre atento a las peculiaridades del caso. Estando los aspectos formales resueltos desde el principio del procedimiento, es posible evitar dilaciones de plazos por dudas y cuestionamientos de orden práctico.

Es importante que el árbitro conozca los puntos en litigio desde el principio, pues cuanta más información tenga antes de esa conferencia, mayores posibilidades tendrá de ayudar a las partes a establecer el procedimiento adecuado en cuanto las cuestiones que deben ser resueltas así, por ejemplo, las pruebas documentales o testimoniales que se requieran, las áreas en las cuales se hará asistir por peritos, y la medida en que requerirá a las partes la exhibición de documentos para resolver los puntos litigiosos, cumpliendo así con su deber de diligencia.

8. Véase ICC, Conducción eficaz del arbitraje: Una guía para abogados internos y para otros representantes de las partes, 2015, disponible en $<\mathrm{http}$ ://goo.gl/VRfYhX $>$. Igualmente, véase ICC, Informe Control del tiempo y los Costos en el Arbitraje, 2008, disponible en <http://goo.gl/lpiUxK>. 
Antes de la audiencia de prueba arbitral, conviene al árbitro estar informado y familiarizado del mérito de los memoriales de demanda, contestación, réplica y dúplica, pues ello le permitirá hacer orientaciones adecuadas a las partes de cuál puede ser la forma más eficiente de enfrentar la prueba y evitar la producción innecesaria o inconducente de pruebas. Este es un tema muy importante, especialmente si una de las partes intenta intencionalmente alargar el procedimiento. La limitación de la extensión y alcance de las presentaciones o escritos puede ser hecho por medio de una orden procesal a las partes de dar una explicación sobre la razón por la cual determinado documento cuya exhibición se requiere es relevante y sustancial para la resolución del caso.

Durante la audiencia de prueba, también el tribunal arbitral deberá ejercer pleno control sobre la producción de pruebas. Quedará a criterio del tribunal limitar o excluir preguntas, respuestas, o la comparecencia algún testigo, si considera que dicha pregunta, respuesta o comparecencia es irrelevante, insustancial, o repetitiva. Cabe también al árbitro conceder la opción de que algún testigo declare por videoconferencia o tecnología similar, en el caso de que no pueda estar presente en el lugar donde se lleva a cabo la audiencia de contra-interrogatorios, lo que puede ser muy útil para no retrasar el calendario procesal previamente establecido, tal como lo instruyen las Directrices de la IBA sobre la prueba9.

La conveniencia de las alegaciones finales deberá ser evaluada por el tribunal después de la audiencia de contra interrogatorios, con el fin de reducir tiempo y costos. Puede ser práctico que el tribunal propicie una lista de cuestiones o puntos a los asesores legales sobre los cuales ellos deban expresarse, en el caso de que las alegaciones se presenten por escrito. Por el hecho de no existir un standard que sirva para todos los arbitrajes, la adaptación del procedimiento al asunto se hace necesaria. Igualmente, las técnicas como la bifurcación del procedimiento o la emisión

9. IBA, Reglas de la International Bar Association (IBA) sobre Practica de Prueba en el Arbitraje Internacional, Artículo 8(1) y 8(2), resolución Aprobada por el Consejo de la IBA, 29/05/2010. 
de un laudo parcial sobre cuestiones preliminares al mérito, pueden hacer el procedimiento más ágil y menos oneroso.

Las características de diplomacia y neutralidad cultural son también muy importantes. Sin diplomacia, el árbitro tendrá una dificultad muy grande de convencer a las partes de las mejores soluciones en términos de procedimiento y convencer además a los demás miembros del tribunal de su punto de vista del caso. La neutralidad es también tema de suma relevancia, pues es necesaria la capacidad de entender el contexto cultural de las posiciones adoptadas por las partes. Así, por ejemplo, un árbitro pro contratante/contratista, con prejuicios geográficos, étnicos o raciales, no tendrá la capacidad de hacer un juzgamiento imparcial.

De acuerdo con DERAINS, "the arbitrators are responsible for the 'nuts and bolts' of the proceedings, but the overall "design" of such proceedings is a matter for the parties and their counsel ${ }^{10 \prime}$. Por lo tanto, para que el procedimiento arbitral sea adecuado y eficaz, hay algunas conductas y prácticas que dependen de los demás involucrados: abogados, partes y secretario arbitral; que pasaremos a analizar.

\section{CoRRECTO DESEMPEÑo COMO ABOgAdo}

La conducta ética de los abogados en arbitrajes internacionales constituye igualmente un tema esencial para el éxito de arbitraje. Es así como los abogados deben actuar en absoluta colaboración con el tribunal, de buena fe y sin el empleo de tácticas dilatorias, de modo de evitar un procedimiento arbitral oneroso y demorado.

El abogado ejerce un papel muy importante desde el principio del procedimiento. En el nombramiento del tribunal, el abogado tiene la función de aconsejar a su cliente para una correcta 10. Y. DeRAINS, N. 6. 
elección de los árbitros. Además, en gran parte, son los abogados quienes conducen el timing de cómo se desarrollará el arbitraje, lo que puede marcar la diferencia entre un procedimiento expedito o no.

Considerando la importancia que tiene el abogado en el buen desarrollo del arbitraje, se espera de ellos una conducta colaborativa y adecuada al reglamento arbitral aplicable. Sin embargo, por involucrar usualmente el arbitraje internacional profesionales de varios países y diferentes culturas, existe una cierta duda por parte de los apoderados de las partes sobre lo que se espera de ellos, ya que cada uno tiene como referencia las reglas éticas aplicables en sus respectivos países.

Atendida la insuficiencia de reglas específicas para el arbitraje internacional, acerca de la actuación de los abogados en los procesos arbitrales, existe una tendencia a la utilización de los códigos o estándares éticos establecidos por instituciones profesionales o tribunales nacionales. Sin embargo, el hecho de que las normas aplicables en cierta cultura no necesariamente sirven para otra distinta, se crea cierta incertidumbre que podría eventualmente llevar a que tenga lugar un trato desigual de las partes, lo que afectaría la integridad del procedimiento.

Generalmente los abogados de parte que participan en arbitrajes internacionales están sujetos a las normas éticas de la jurisdicción a la que pertenecen, pudiendo también estar sujetos a las normas del lugar sede del arbitraje, tal como establecen los Principios Internacionales de Conducta para la Profesión Jurídica de la IBA ${ }^{11}$. Este problema de la doble regulación a que los apoderados pueden estar sujetos es conocido como la doble deontología. Ello significa que muchas veces los abogados además de actuar de conformidad con los estándares de conducta nacionales pueden estar sujetos a otras reglas o normas éticas que sean diferentes o ajenas a sus costumbres. Además de la doble regulación, suele ocurrir que los abogados que estén participando en arbitrajes in-

11. Este Código sustituyó al Código de Conducta de la IBA, el 28/05/2011. Véase <http://goo.gl/BylkH8>. 
ternacionales se vean en el deber de seguir y respetar también parámetros internacionales.

El trato justo y equitativo a las partes es un principio básico de todo arbitraje internacional. Por lo tanto, es en la garantía de ese principio que radica la importancia del tema, ya que éste debe mantenerse a pesar de existencia de las diferentes exigencias ontológicas y conductas que adoptan los abogados al basarse en diferentes reglas de ética profesional.

Las disímiles expectativas originadas por diferentes culturas éticas podrían llegar a generar desigualdades que pudieran afectar el trato justo y equitativo de las partes y su capacidad de presentar o defender su caso. Esta diversidad de reglas se presenta más evidente en el ámbito del arbitraje de inversión, donde comúnmente los abogados son de los más distintos orígenes y culturas $^{12}$.

Con todo, existen algunos estándares internacionales relacionados con la conducta de los abogados de parte. En el año de 1956 la IBA promulgó un Código Internacional de Ética para los Abogados, recientemente actualizado en 2011. La nueva versión -de manera distinta a la primera, que traía recomendaciones generales- trae especificados diez puntos que el abogado debe observar; a saber:

a) independencia: ofrecimiento de asesoría y representación imparcial a clientes, incluso en cuanto a las probabilidades de éxito del caso.

b) honestidad, integridad y justicia: El abogado deberá mantener en todo momento los estándares más altos de honestidad, integridad y justicia hacia los clientes, los tribunales, colegas $\mathrm{y}$ todos aquellos con quien el abogado entre en contacto profesional.

12. C. Brower y S. SCHILL "Regulating counsel conduct before international arbitral tribunals", Making Transnational Law Work in the Global Economy. Cambridge University Press, 2010. Disponible en $<\mathrm{http}: / /$ goo.gl/yh59SE $>$. 
c) conflictos de interés: El abogado no deberá asumir una posición en la que los intereses del cliente entren en conflicto con los intereses del abogado, de otro abogado en la misma firma, $\mathrm{u}$ otro cliente.

d) confidencialidad/secreto profesional: El abogado deberá mantener la protección de confidencialidad respecto a los asuntos de clientes actuales o pasados.

e) Intereses de clientes: El abogado deberá tratar los intereses de clientes como primordiales.

f) compromisos del abogado: El abogado deberá honrar de manera oportuna cualquier compromiso dado en el curso de su práctica como abogado.

g) libertad del cliente: El abogado deberá respetar la libertad del cliente de ser representado por el abogado de su elección.

h) protección de la propiedad del cliente y de terceros: El abogado deberá dar cuenta puntual y fielmente, y mantener prudentemente cualquier propiedad de clientes o terceros que le sean confiados.

i) competencia: El abogado no deberá aceptar encargos que, razonablemente, no considere poder llevar a cabo de manera apropiada.

j) honorarios: Los abogados tienen derecho a honorarios razonables por su trabajo, y no deberán cobrar honorarios irrazonables.

En el ámbito europeo, el Consejo de la Abogacía Europea (CCBE) ha adoptado un código y una carta de principios fundamentales de la abogacía. Sin embargo, éstas reglas no abordan la problemática y particularidades del arbitraje internacional. Existen también The Hague Principles on Ethical Standards for Conseul Appearing before International Courts and Tribunals (2010), que son principios no vinculantes para los abogados de parte ante un tribunal de derecho internacional, incluyendo los tribunales arbitrales internacionales que involucran un Estado como parte, y The international Code of Ethics for Lawyer Practing Before International Arbitral Tribunals. 
En forma más reciente, se han formulado las Directrices de la IBA sobre Representación de Parte en el Arbitraje Internacional ${ }^{13}$ que, entre otras normas, establecen:

i) que una vez constituido el tribunal arbitral, una persona no debe aceptar la representación de una parte en el arbitraje si existe una relación entre dicha persona y un árbitro que crearía un conflicto de intereses, a menos que ninguna de las partes objete una vez que se efectúe la revelación (directriz 4);

ii) un representante de parte debe abstenerse de incurrir en cualquiera comunicaciones ex parte con un árbitro que se relacionen con el arbitraje, como regla general. Excepcionalmente, están permitidas si se refieren a las comunicaciones con un posible árbitro, en cuyo caso se deben limitar a proveer una descripción general de la controversia y obtener información relativa a la idoneidad del posible árbitro (directrices 7 y 8 );

iii) el representante de parte no debe hacer ninguna declaración de hecho falsa ante el tribunal arbitral; tampoco debe presentar probanzas de testigos o peritos que sepa que son falsas (directrices 9-11);

iv) un representante de parte debe informar al cliente acerca de la necesidad de preservar, en la medida de lo razonablemente posible, documentos que pudieran ser potencialmente relevantes para el arbitraje; como igualmente, no debe presentar solicitud de exhibición de documentos u objetar cualquier solicitud de exhibición de documentos, por motivos indebidos, tales como hostigar o causar demora innecesaria (Directrices 12-17);

v) un representante de parte puede ayudar a testigos o peritos en la preparación de su declaración testimonial o en la elaboración de su dictamen, respectivamente, pero debe asegurarse de que la declaración o dictamen refleje la propia versión del testigo de los hechos, eventos y circunstancias relevantes y tratándose del perito que refleje su propio análisis y opinión (Directrices 18 a 25).

13. Resolución Aprobada por el Consejo de la IBA, 25/05/2013. 
De esta forma, queda claro que la conducta ética que deben observar los apoderados de las partes es una postura colaborativa con el Tribunal. Conductas poco razonables como excesivas solicitudes de presentación de documentos, presentación de documentos confidenciales de la contraparte obtenidos de forma inapropiada, argumentos jurídicos insostenibles, contrainterrogatorios excesivos, tácticas dilatorias, pretensiones desmedidas, el no respeto a las órdenes procesales, solicitudes de medidas provisionales injustificadas, y el no respeto al calendario procesal sin justa causa son ejemplos de conductas inaceptables para lograr un eficiente procedimiento arbitral.

Para desalentar esas conductas procesales poco razonables, el artículo 37 del Reglamento de Arbitraje de la ICC ${ }^{14}$ (International Chamber of Commerce) establece que al resolver sobre el reparto de las costas del arbitraje, el Tribunal tendrá en cuenta "las circunstancias que considere relevantes, incluyendo la medida en que cada parte haya conducido el arbitraje de forma expedita y eficaz en términos de costos". Dicha norma incentiva el cumplimiento de las mejores prácticas arbitrales por las partes y sus abogados durante la tramitación del procedimiento.

El tribunal puede también hacer el uso de otras herramientas, como la determinación de la exclusión de documentos confidenciales del conjunto probatorio, la determinación de llegar a una inferencia negativa en cuanto a ciertas pruebas (cuando una de las partes se rehúse a cooperar durante la exhibición de documentos o guarde silencio en cumplir una orden del tribunal sin excusa razonable para hacerlo), e incluso la descalificación del asesor de parte en casos extremos ${ }^{15}$.

Igualmente, de acuerdo a las Directrices de la IBA sobre Representación de Parte, el tribunal arbitral puede adoptar diversas

14. Véase $<$ http://goo.gl/1p0hgQ $>$.

15. H. Álvarez y M. Jiménez GonzÁlez, "Los estándares éticos aplicables a los abogados de parte en el arbitraje internacional”, Arbitraje Internacional: pasado, presente y futuro, Coordinadores: C. CoAGuila y D. Revoredo Marsano De Mur, Tomo I, Instituto Peruano de Arbitraje: Lima, 2013, pp. 199 y ss. 
medidas frente a una conducta indebida de los representantes de las partes; a saber:

i) amonestar al representante de la parte;

ii) hacer inferencias apropiadas al evaluar las pruebas utilizadas por el representante de la parte;

iii) considerar la conducta indebida del representante de la parte al momento de distribuir los costos del arbitraje;

iv) tomar cualquier otra medida que sea necesaria a efectos de preservar la justicia e integridad del procedimiento (Directrices 26 y 27).

\section{CORRECTO DESEMPEÑO COMO PARTES}

A pesar que existan pocas referencias sobre la ética que las partes deben observar en un arbitraje, lo normal es que el tribunal espere mínimamente de ellas una conducta respetuosa con el convenio arbitral y con las exigencias que derivan del procedimiento arbitral acordado al igualmente que el cumplimiento de las reglas de tramitación del arbitraje adoptadas. Por ser un procedimiento privado, donde el árbitro carece del poder de coacción, el arbitraje depende en gran parte de la buena fe en la actuación de las partes.

En relación al acuerdo de arbitraje, una mala práctica -más habitual que lo esperado- es el ejercicio injustificado de la acción en la vía judicial, a pesar de la existencia de un convenio arbitral incuestionablemente válido y celebrado voluntariamente entre las partes. Tal actitud culmina en un inevitable retraso para la resolución de la cuestión jurisdiccional y la onerosidad del procedimiento.

Otra mala práctica muchas veces usada por las partes son las recusaciones infundadas o frívolas sucesivas, con el único objetivo de postergar el procedimiento. Lo mismo puede decirse de aquellos casos en que una de las partes trata de obstruir judicial- 
mente el procedimiento de designación de los árbitros -a pesar de haber acordado la aplicación de un reglamento de arbitraje que prevea tal procedimiento-, con el único propósito de dilatar el comienzo del arbitraje.

Igualmente, donde es común la violación de buenas prácticas por las partes es en la solicitud injustificada y abusiva de la prórroga de plazos para el cumplimiento de ciertas cargas procesales, casi siempre acompañada de la amenaza de que la negativa por parte del tribunal arbitral constituiría denegación de oportunidad de presentar el caso o hacer valer sus derechos. No menos comunes son las veces en que las partes se ponen de acuerdo sobre el procedimiento y los plazos y aun así, alguna de ellas hace peticiones unilaterales no previstas en el procedimiento o presenta documentos fuera del plazo, lo que implica que el arbitraje se vea enfrentado con etapas no previstas en las reglas de procedimiento.

No es raro que una de las partes haga una solicitud y, frente a la negativa de esta, la parte reformule la misma solicitud bajo otros argumentos tantas veces cuantas pueda. Esta mala práctica, no solamente es mal vista por los árbitros, que tienen que decidir varias veces sobre el mismo tema, pero también usualmente implica que el calendario procesal se vea retrasado, pudiendo, en definitiva, causar dilación innecesaria en la resolución del arbitraje.

La conducta colaborativa de las partes también se pone a prueba cuando se trata de las audiencias. Muchas veces la falta de comparecencia de testigos o peritos es usada como un medio para la repetición del acto en nueva fecha. Cuando se trata de permitir a la parte contraria y a sus peritos el acceso a las instalaciones propias o a documentos de los que se tiene control, otra vez se pone a prueba la cooperación procesal de las partes. Grave violación de los principios y deberes de cooperación procesal son también el ocultamiento o destrucción de pruebas, además de constituir una práctica totalmente contraria a la ética arbitral. 
La última oportunidad que resta a una parte que actúa de mala fe en un arbitraje es buscar la nulidad del procedimiento, o bien intentar obstruir su reconocimiento y ejecución. A pesar que puedan existir situaciones en que la parte perdedora realmente tenga fundamentos para pedir la anulación del laudo o la denegación de su reconocimiento o ejecución, existen otros casos en que esto no ocurre, y de la misma forma la parte perdedora usa de estos artificios únicamente como táctica dilatoria.

\section{CORRECTO DESEMPEÑO COMO SECRETARIO ARBITRAL}

Por último, tratándose del secretario arbitral, esto es, de la persona que ayuda al árbitro en la parte administrativa, organizacional y de investigación del arbitraje, constituye usualmente un apoyo muy útil para una eficiente administración de un arbitraje, especialmente si no existe el apoyo de una institución administradora, por tratarse de un arbitraje ad-hoc.

Generalmente, el árbitro sugerirá a las partes un secretario arbitral cuando el caso por su complejidad jurídica o administrativa lo exija. De acuerdo con el Young International Council for Comercial Arbitration Guide on Arbitral Secretaries ${ }^{16}$, el tribunal arbitral debe contar con el consentimiento de todas las partes antes de nombrar el secretario, que debe estar sujeto a las mismas reglas de confidencialidad y privacidad a que está sujeto el árbitro.

Como el arbitraje es un procedimiento privado donde las partes tienen amplia libertad para establecer algunas reglas, no sería distinto tratándose de la nominación del secretario arbitral, de modo que las partes pueden hacer objeciones si así les pareciere. Si la objeción al secretario es fundada, basada en un verdadero conflicto de intereses, el tribunal debe proseguir sin el secretario o nombrar a otro. Sin embargo, si la objeción de la(s)

16. YouNG ICCA, “Guide on Arbitral Secretaries", The ICCA Reports, 2014(1), véase <http://www.arbi-
tration-icca.org/>. 
parte(s) se da en términos generales (por ejemplo, con el argumento de los costos asociados), el tribunal debe considerar las circunstancias del caso para determinar si el nombramiento del secretario es realmente necesario para la resolución eficiente y eficaz de la disputa, aunque la posición de la(s) parte(s) sea discordante.

De acuerdo con la guía de la ICCA, el rol del secretario arbitral incluye básicamente:

(a) La ejecución de las cuestiones administrativas que sean necesarias en ausencia de una institución arbitral;

(b) Comunicar a la institución arbitral y las partes las resoluciones adoptadas por el tribunal arbitral;

(c) La organización de reuniones y audiencias con las partes;

(d) Manejo y organización de la correspondencia, las comunicaciones y las pruebas en nombre del tribunal arbitral;

(e) Investigar las cuestiones de derecho;

(f) Investigar cuestiones relativas a las pruebas fácticas y declaraciones de testigos;

(g) Elaboración de resoluciones u órdenes procesales y documentos similares, bajo la supervisión del tribunal;

(h) Revisar los escritos de las partes y pruebas, y la elaboración de cronologías de hechos y memorandos que resumen sus argumentos y pruebas de las partes;

(i) Asistir a las deliberaciones del tribunal arbitral; y

(j) Hacer el borrador de la posición de las partes para el laudo arbitral, bajo la supervisión del tribunal (no siendo de competencia del secretario hacer los argumentos legales de la decisión).

Sin embargo, es discrecionalidad del tribunal determinar los deberes y responsabilidades que pueden ser confiadas al secretario. Es responsabilidad de los árbitros revisar todos los documentos clave acompañados o hechos valer por las partes. No obstante, la asistencia de un secretario arbitral para revisar todo el expediente probatorio a fin de investigar controversias relacio- 
nadas con las pruebas fácticas y testimonios es una buena práctica que puede agregar valor y eficiencia al proceso.

Lo que ocurre en la práctica es que muchos árbitros hacen responsablemente un uso más completo de secretarios arbitrales diligentes, más allá de la función puramente administrativa, para ayudar a ellos en el desempeño de sus funciones, sin que ello implique de modo alguno que los árbitros se vean liberados de sus funciones esenciales tanto en la conducción del procedimiento arbitral como en la resolución del asunto controvertido. Sin embargo, el tema de los límites de las atribuciones del secretario arbitral no está todavía bien y suficientemente desarrollado, sin que exista uniformidad acerca del límite de las tareas que los árbitros pudieran delegar.

Lo que es indiscutible es que el hecho del tribunal de contar con un secretario arbitral puede ser una buena práctica. Es sabido que los árbitros, generalmente, son personas muy ocupadas y que, por veces, no tienen tiempo suficiente para ordenar, sistematizar y procesar toda la documentación que se le entrega, el contacto con las partes y la administración que el arbitraje necesita, especialmente cuando se trata de un procedimiento ad hoc, en que no se cuenta con una institución que apoye en la administración del arbitraje. El secretario arbitral puede dedicar más tiempo a investigar las cuestiones, revisar los escritos de las partes y pruebas y coordinar la preparación de las audiencias, lo que auxilia y optimiza mucho el trabajo del árbitro, contribuyendo para que el procedimiento sea expedito.

\section{CONSIDERACIONES FINALES}

Como hemos podido apreciar, la conducción de todo arbitraje comercial internacional en aras a lograr una solución justa, expedita y especializada dentro de plazos razonables supone como pieza fundamental contar con un árbitro, que no solo reúna las condiciones de imparcialidad e independencia propias de 
todo juzgador, sino que también tenga adicionalmente, entre otras cosas, la habilidad de decidir, disponibilidad, capacidad de trabajar intensamente, diplomacia y neutralidad cultural, asumiendo un rol pro-activo en la conducción del procedimiento arbitral, dando las garantías para que cada parte pueda hacer valer oportunamente sus derechos, y que la prueba que se rinda sea pertinente y conducente a poder resolver en forma adecuada los puntos litigiosos, lo que le permita dictar un laudo que se pueda ejecutar. Sin embargo, resulta también fundamental contar con la adecuada actitud de colaboración tanto de los apoderados o representantes de las partes como de éstas mismas, para lo cual constituye una herramienta muy útil tener en consideración las Directrices establecidas especialmente por la IBA antes analizadas, que recogen las buenas prácticas para una mejor conducción del procedimiento arbitral. Igualmente, es muy útil que el tribunal arbitral pueda contar con el apoyo de un secretario arbitral, que contribuya a que el procedimiento arbitral pueda ser llevado a cabo en forma eficiente, especialmente en la parte administrativa, organizacional y de investigación del arbitraje, todo lo cual redundará en definitiva en un mejor arbitraje. 